\title{
The seismicity of central and north-east Himalayan region
}

\author{
Susheel KUMAR ${ }^{1}$, Nitin SHARMA SH, $^{1,2}$ \\ ${ }^{1}$ Indian Institute of Geomagnetism, Navi Mumbai 410218, India \\ ${ }^{2}$ CSIR - National Geophysical Research Institute, Hyderabad 500007, India
}

\begin{abstract}
The Himalayan range extends upto $2400 \mathrm{~km}$ arc from Indus river valley in the west to Brahmaputra river valley in the east of India. Due to distinct geological structures of Himalayan seismic belt, seismicity in Himalaya is inhomogeneous. The inhomogeneity in seismicity is responsible for a number of seismic gaps in the Himalayan seismic belt. Thus Iin the present study, we proposed the study of spatial and temporal evolution of seismicity in entire central and north-east Himalayan region by using Gutenberg-Richter relationship. A detailed study on the behavior of natural seismicity in and around the seismic gap regions is carried out. The study region is segmented in four meridional regions (A) $80^{\circ} \mathrm{E}$ to $83.5^{\circ} \mathrm{E}$, (B) $83.5^{\circ} \mathrm{E}$ to $87.5^{\circ} \mathrm{E}$, (C) $87.5^{\circ} \mathrm{E}$ to $90^{\circ} \mathrm{E}$ and (D) $90^{\circ} \mathrm{E}$ to $98^{\circ} \mathrm{E}$ along with a fixed latitude belt. The homogeneous catalogue with $3 \leq M_{b} \leq 6.5$ is used for the spatial and temporal analysis of seismicity in terms of $b$-value. It is find out that pockets of lower $b$-values are coinciding over and around stress accumulated regions. The observed low $b$-value before occurrence of the Nepal earthquake of 25th April, 2015 supports the argument of impending occurrence of moderate to large magnitude earthquake in Sikkim and north-east Himalayan region in future.
\end{abstract}

Key words: central and north-east Himalaya, natural seismicity, Gutenberg-Richter relationship, $b$-value

\section{Introduction}

The central and north-east Himalayan regions are prone to medium and large magnitude earthquakes. The Kangra earthquake of $1905\left(M_{s} 8.0\right)$, Nepal (Bihar) earthquake of $1934\left(M_{w} 8.4\right)$, Assam earthquake of 1950 $\left(M_{w} 8.3\right)$, Kashmir earthquake of $2005\left(M_{w} 7.8\right)$ and Gorkha, Nepal earthquake of 25th April, $2015\left(M_{w} 7.8\right)$, etc. are some examples in this context. The collision of a fast moving Indian continental plate $(\sim 45 \mathrm{~mm} /$ year $)$ with the slow Eurasian plate $(\sim 2-3 \mathrm{~mm}$ /year $)$ resulted in the formation of the

\footnotetext{
*corresponding author: e-mail: withnitin@gmail.com
} 
Kumar S., Sharma N.: The seismicity of central and north-east Himalayan ... (265-281)

Himalayas and the attendant seismic belt. This belt currently consists of the Himalayan mountain ranges, Tibet plateau and other highest mountain ranges including the Everest (e.g. Gansser, 1964; Valdia, 1976). The first collision between the Indian and Eurasian plates invoked the main central thrust (Zhao et al., 1993) (MCT) fault before $\sim 23 \mathrm{Ma}$ and it was active for $\sim 12 \mathrm{Ma}$. In the process of continuous convergence, the main boundary thrust (MBT) fault was formed before $\sim 11 \mathrm{Ma}$ and was active up to $\sim 3 \mathrm{Ma}$. The Main frontal thrust (MFT) fault was formed further south of MBT before $\sim 2 \mathrm{Ma}$ and is still active (Avouac, 2003). The convergence of the Indian plate across the MFT fault is $\sim 20 \mathrm{~mm} /$ year (e.g. Ader et al., 2012 and references therein). The time evolution of these faults depicts that seismicity has migrated southwards (Yeats and Thakur, 1998) in the last $\sim 30 \mathrm{Ma}$.

The studies like Thakur (2004) and Mukhopadhyay (2011) have claimed that some geological portions of the region between the MCT and the Suture zone (Indian and Eurasian plate) are reactivated to yield the observed seismicity of this region. The most devastating earthquakes of India occurred near the MBT and MFT regions during last 125 years. This corroborates that these two faults are still active from seismicity point of view. All the three main faults (MCT, MBT and MFT) terminate at the low dipping $\left(5^{\circ}-\right.$ $16^{\circ}$ ) plane of detachment or a common mid-crustal decollement known as the main Himalayan thrust (MHT) (Molnar and Lyon-Ceant, 1989; Schelling and Arita, 1991; Sapkota et al., 2013). The earthquake sources rupture and propagate southwards along the plane of detachment, MHT (Sapkota et al., 2013; Sreejith et al., 2016). Most of the thrust fault motion (Fitch, 1970; Zhao and Helmberger, 1991) consists of slip on the main Himalayan thrust (MHT) fault which is a shallow dipping $\left(5^{\circ}-16^{\circ}\right)$ mid-crustal ramp structure (Pandey et al., 1995, 1999; Cattin and Avouac, 2000; Caldwell et al., 2013, Sreejith et al., 2016). It can be seen from the seismological catalogue (Ni and Barazangi, 1984; Kayal, 2001, 2010) that most of the decollement earthquakes occur in the depth range $\sim 11-20 \mathrm{~km}$ (i.e. within upper crust) which coincides with MHT in the southern Himalaya. While, the MFT is the main surficial visualisation of crustal shortening between the Himalaya and the Indian plate (Sapkota et al., 2013).

The natural seismicity of any continental-continental collision zone can be classified as pre-seismic, co/inter-seismic and post-seismic cycles (Bilham 
et al., 1997 and Cattin and Avouac, 2000; Avouac, 2003; Jade et al., 2007; Mukul et al., 2010; Jade et al., 2014). It is generally difficult to demarcate temporal boundaries between these cycles. The advent of digital instrumentation and improved networks World-Wide Standardized Seismological Network (WWSSN) standards under the U.S. Geological Survey (USGS) collaboration) resulted in accurate catalogue data (Bhattacharya and Dattatrayam, 2000). It is now possible to identify prolongation of a cycle based on precise information of the current and past cycles. It should be noted here that the nature of these cycles depends on the fault parameters, tectonic slip or locking, geographic and climatic conditions, geological heterogeneity and stress barriers. We attempt to study the nature of the impending seismicity associated with these cycles using the information available from the current and past seismic behaviour of the central and north-eastern Himalayan regions $\left(80^{\circ} \mathrm{E}\right.$ to $98^{\circ} \mathrm{E}$ in four meridional regions - Fig. 1$)$.

As the main thrust faults lie in the latitude belt of $\sim 26^{\circ} \mathrm{N}$ to $30^{\circ} \mathrm{N}$, we thus restrict the current study bounded by the above said latitude and longitude intervals. Fig. 1 depicts the selected study area which is again divided into four different longitude sub-regions: (A) $80^{\circ} \mathrm{E}$ to $83.5^{\circ} \mathrm{E}-$ Western Nepal region, (B) $83.5^{\circ} \mathrm{E}$ to $87.5^{\circ} \mathrm{E}-$ Central Nepal region, (C) $87.5^{\circ} \mathrm{E}$ to $90^{\circ} \mathrm{E}-$ Eastern Nepal and Sikkim region and (D) $90^{\circ} \mathrm{E}$ to $98^{\circ} \mathrm{E}-$ Bhutan, Assam and Arunachal Pradesh region. These longitudinal bins are made on the basis of disposition of the tectonic and geological structures in the studied region (Adhikari and Paudyal, 2015) which indicates scattered seismicity confined to northern part of MCT in western part of Nepal to north-west of Himalayan in India and MBT to MFT in central to eastern part of Nepal. The significantly low seismicity with time is observed in crustal homogeneity and various barriers e.g. faults/ridges/rifts area of Central Nepal (Fig. 1). The segmented A, B, C and D bins shown in Fig. 1 also depict the main tectonic features such as prominent ridges and grabens, important lateral strike-slip and thrust faults, besides other lineaments that lay in the selected study sub-regions. It is to be mentioned that the above said four regions are chosen to exclusively consider the seismicity of the continental-continental collision margins and effective stress/strain rate. The four subdivision are done to analyse the spatio-temporal variations of $b$-value precisely. Moreover each sub-region comprises seismic gaps (central seismic gap and distinct tectonic features such as fault friction and geometry which might affect the 
behaviour of the seismicity and magnitude of earthquake in sub-regions as mentioned in previous studies (Bilham et al., 2001; Dal Zilio et al., 2019).

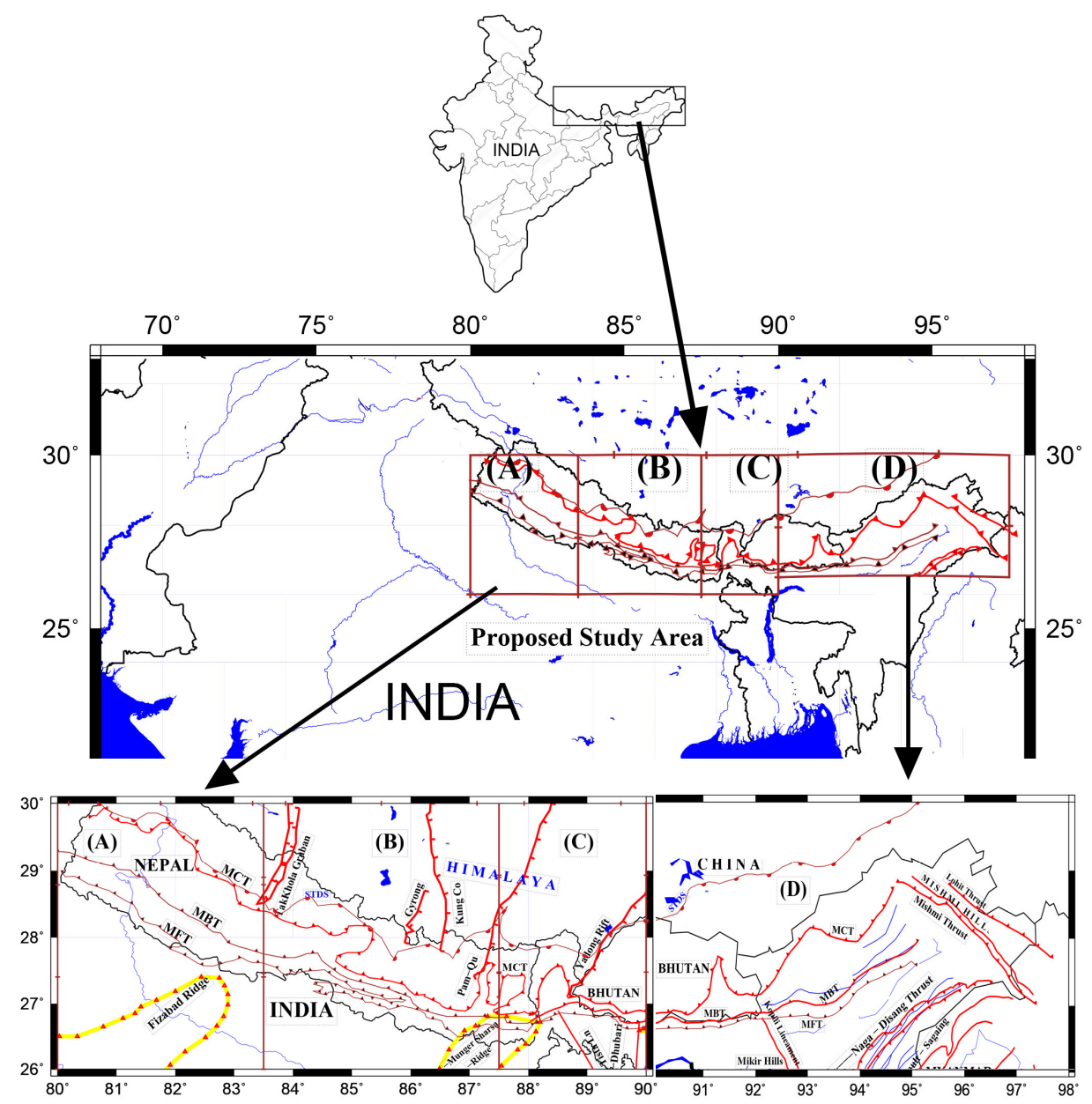

Fig. 1. Segmentations of study area are marked on basis of tectonics as regions A,B,C and D (marked rectangular blocks). STDS (South Tibetan Detachment), MFT is marked half circle and triangles on brown lines. The MBT, MCT major thrust faults marked with triangles on red line and other faults are shown in red lines. Ridges are marked with yellow lines with red triangles. Graban and rift in northern part are shown as red line with tick marks. 
The objectives of the present study are to document spatial and temporal changes in frequency-magnitude distribution (FMD) related to the demarcated regions and their association with earthquake occurrence of a certain threshold magnitude (Pudi et al., 2018; Dal Zilio et al., 2019). Based on the characteristic features in the seismic rates, specific to the thrust regions of central and north-eastern Himalaya, we attempt to identify the most probable locations of impending earthquakes in tectonically active region associated with spatial $b$-value $<1.0$.

The well-known Gutenberg-Richer law (Ishimoto and Iida, 1939; Gutenberg and Richer, 1954, 1944) thus forms the main foundation to the present study. This relation can be formulated as:

$\log N=a-b M$.

In Eq. (1) $a$ and $b$ are constants, $b$-value (slope of frequency-magnitude distribution (FMD)) represents tlogarithmic ratio of the number of earthquakes $(N)$ with magnitude of earthquakes $(M)$ while $a$-value represents the overall seismicity. Various studies have used this equation to depict that, in a stressed region, if the number of small magnitude earthquakes are high then the possibility of occurrence of a large magnitude earthquake will be less. A low $b$-value indicates that the effective stress in the boundaries of rocks is still in an accumulation phase, and is likely to be released at any point of time by way of a large earthquake or total equivalent energy in multiple moderate size events. While, a high $b$-value suggests that the regional heterogeneity or crack density is high and is transforming into a low stressed regime (Wyss, 1973; Tsapanos, 1990; Nuannin et al., 2005; Parsons, 2007). The spatial and temporal variations of $b$-value can be used to understand the physical behaviour of stress or strain rate in the tectonically characteristic of theactive region. The high spatial variation of $b$-value is a meter to say that stress, has already normalized the differential stress. Therefore, the $b$-value serves as the main parameter in the present study. The studies based on similar concepts have shown promising results for e.g. studies carried out in Taiwan, by Chan et al. (2012) and Prasad and Singh (2015) in Andaman subduction region, Pudi et al. (2018) in western India to central Nepal, Sreejith, et al. (2016); Sreejith et al. (2018) Gorkha earthquake $\left(M_{b}\right.$ $6.9, M_{w} 7.6$ ISC) in central Nepal region of Nepal. 
Kumar S., Sharma N.: The seismicity of central and north-east Himalayan ... (265-281)

\section{Data and Methodology}

The availability of large data is a basic requirement for any systematic scientific study. We use the homogeneous earthquake catalogue of USGS, ISC and ANSS(Advanced National Seismic System), with only body wave magnitude scales ranges from $3 M_{b}$ to $6.9 M_{b}$. Though, catalogues are available from 1950 onwards, but public data continuity and accuracy in $M_{b}$ were observed better after 1974 in the study region (Bhattacharya and Dattatrayam, 2000).

To compute $b$-value, self-similarity of earthquake process which consequently implies a power law in the distribution of earthquakes in terms of magnitude is assumed. An estimate of reasonably accurate $b$-values can be obtained using equation given below (Aki, 1965; Bender, 1983; Utsu 1999):

$b=\frac{\log _{10} \mathrm{e}}{\langle M\rangle-\left(M_{c}-\frac{\Delta M_{b i n}}{2}\right)}$,

where $\langle M\rangle=$ mean magnitude, $M_{c}=$ magnitude of completeness, $\Delta M_{b i n}$ $=$ binning width of magnitude of completeness, i.e. 0.1 or 0.2 .

$M_{c}$, completeness of Catalogue, is more crucial in $b$-value study and an important parameter. The high value of $M_{c}$ will represent to under sampling of events, while low value of $M_{c}$ will represent erroneous seismicity. The $\mathrm{M}_{c}$ value is computed by normalisation of the ratio between the frequency of earthquake and magnitude of earthquake (Rydelek and Sack, 1989). To calculate it we used the Entire Magnitude Range (EMR) method (Woessner and Wiemer, 2005, further modified after Ogata and Katsura, 1993). In order to maintain the self-similarity of the catalogues for all the regions, we therefore discarded the smaller magnitude earthquakes of $M_{b}<3$. Thus body wave magnitude $\left(3 \geq M_{b} \leq 6.9\right)$ is considered for the analysis as per available catalogue of this region. In the present study, declustering of aftershocks from the catalogue is accomplished using a moving space and time window (Uhrhammer, 1986). The events in regions A, B and C are 350, 777 and 615 respectively and add up to 1732 events, while 1010 events falls in the $\mathrm{D}$ region. Using these declustered data from homogenous catalogues for each region, the respective spatial and temporal $b$-values are estimated. The analysis is performed by making bin of 50 events (minimum number of events 
in each node) (Parsons, 200\%) with an overlap and smoothing of 5 events, adopting bootstrap of 20 realisations and grid spacing of $0.1 \times 0.1$. The $M_{c}$ value for region $\mathrm{A}$ is $3.9 \pm 0.13, b$-value $=0.73 \pm 0.12$ shown in Fig. $2 \mathrm{a}$, in B region $M_{c}=3.9 \pm 0.19, b$-value $=0.81 \pm 0.12$ shown in Fig. $2 \mathrm{~b}$ and $M_{c}$ of $\mathrm{C}$ region is $3.9 \pm 0.11, b$-value $=0.88 \pm 0.06$, shown in Fig. $2 c$. The $M_{c}$ and $b$-value of combined A, B and $\mathrm{C}$ region ( $1110 \mathrm{~km}$ segment) i.e. $M_{c}=3.9 \pm 0.14$, $b$-value $=0.69 \pm 0.06$ are in the similar range of $\mathrm{A}, \mathrm{B}$ or $\mathrm{C}$. Similarly, $M_{c}$ value of $\mathrm{D}$ region is $3.9 \pm 0.1$ and $b$-value $=0.75 \pm 0.05$ shown in Fig. $2 \mathrm{~d}$. The value of $M_{c}$ in all $\mathrm{A}, \mathrm{B}, \mathrm{C}$ and $\mathrm{D}$ regions are significantly same though $b$-value is varying which signifies different seismicity behaviour in four subregions.
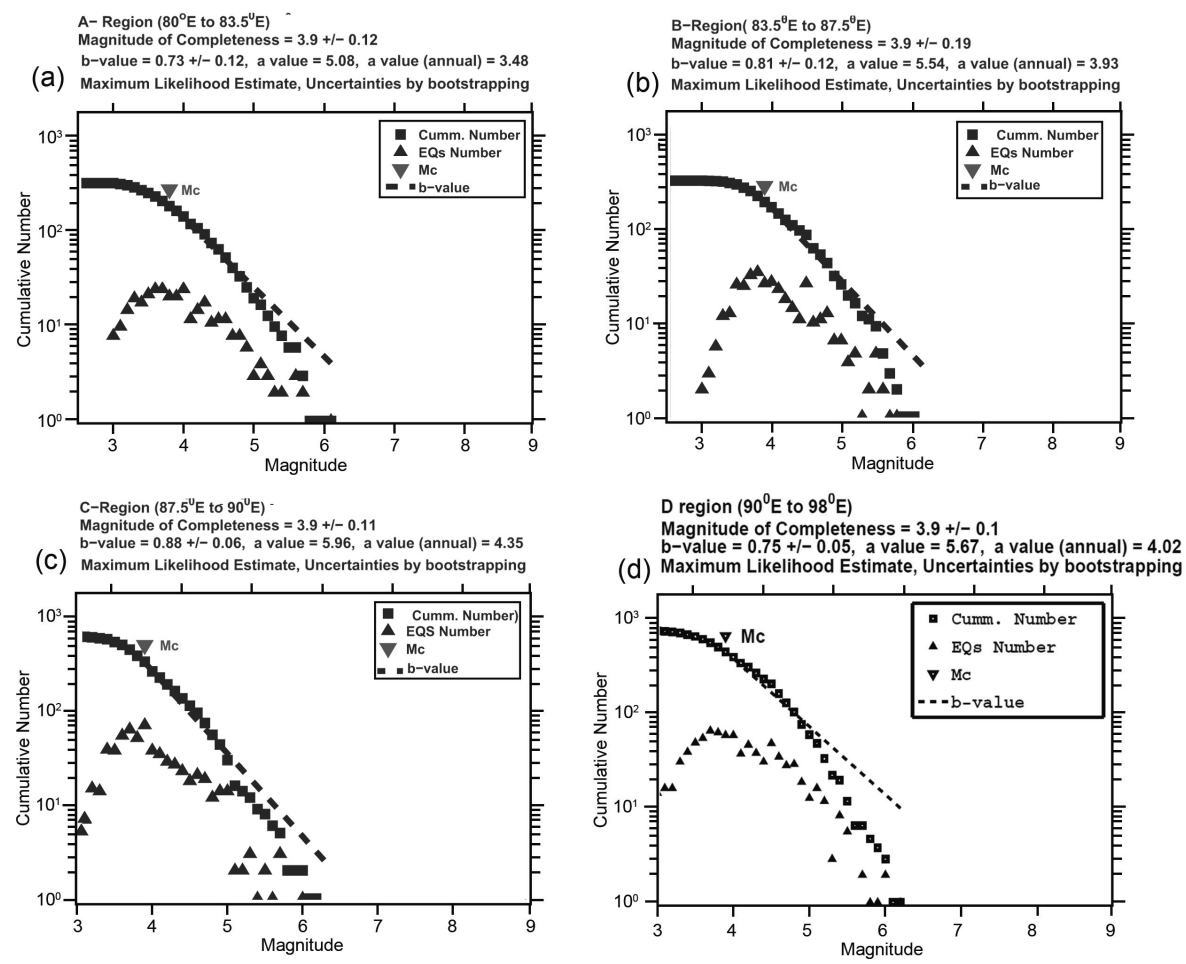

Fig. 2. Computed $M_{c}$ - magnitude of completeness value (a) for A region (Central-western Nepal), (b) for B region (Central Nepal), (c) for C region (Eastern Nepal, Sikkim and Western Bhutan) and (d) for D region. 
Kumar S., Sharma N.: The seismicity of central and north-east Himalayan ... (265-281)

\section{Results and Discussion}

The seismicity and the spatial variations of $b$-value over latitudes of $\sim 26^{\circ}$ $\mathrm{N}$ to $30^{\circ} \mathrm{N}$ (fixed) and longitudes of $80^{\circ}$ to $90^{\circ} \mathrm{E}$ (A, B and $\mathrm{C}$ regions as defined earlier) is shown in Fig. 3a. The variations are presented over a latitude-longitude grid of $1^{\circ} \times 1^{\circ}$. The total temporal span is from 1975 to 2015 (40 years). It could be observed that most of the seismic events $\left(M_{b} \geq 5\right)$ have occurred in the areas of low $b$-value. We suggest that the depletion in $b$-value depending upon the seismicity of the given region can indicate the occurance of moderate to large magnitude earthquake. For example, the region between $28.25^{\circ} \mathrm{N}-29^{\circ} \mathrm{N}$ and $84.5^{\circ} \mathrm{E}-86.5^{\circ} \mathrm{E}$, with a very low $b$-value, hosts epicentres of the recent large Gorkha earthquake of Nepal on 25 April 2015 and 12 May 2015 (Fig. 3a). The low $b$-value shown in the spatial variation map (Fig. 3a) clearly suggests that this region is still developing stress which might release (Sreejith et al., 2016; Sreejith et al., 2018) in the form of a large earthquake or equivalent few moderate ones.

The $b$-values around the epicentre $\left(26.77^{\circ} \mathrm{N}, 86.69^{\circ} \mathrm{E}\right)$ of the famous 1934 Bihar-Nepal earthquake of $\sim 8.4 M_{w}$ that was followed by an event of $\sim 6.9$ $M_{w}\left(26.71^{\circ} \mathrm{N}, 86.62^{\circ} \mathrm{E}\right)$ on 21 August 1988 are observed to remain high. This indicates that significant amount of differential stress around this area is being due for future earthquake. In further east, the region with a low $b$-value associated with deformed shape (major swerve) of MCT may spawn a large earthquake in the future. An earthquake of $6.5 M_{w} 18$ September, 2011 (Sikkim earthquake, $27.80^{\circ} \mathrm{N} 88.15^{\circ} \mathrm{E}$ ) in this region has already occurred.

The Assam region including Arunachal Pradesh and Bhutan is covered under D-region in Fig. 3b. This covers latitude belt from $26.5^{\circ} \mathrm{N}$ to $30^{\circ} \mathrm{N}$ and longitude belt from $90^{\circ} \mathrm{E}$ to $98^{\circ} \mathrm{E}$. The $\mathrm{C}$ and D-regions are separated by Goalpara ridge at $90^{\circ} \mathrm{E}$ and north-south trending Dhubari fault and Yamuna lineament that extends till the southern part of Himalayan belt. This ridge is sandwiched between the Himalayan belt and Shillong plateau. The northward dipping of east-west extended Oldham fault during the great 1897 Assam earthquake uplifted the land of $\sim 1 \mathrm{~m}$ (Bilham et al., 2001) and enhanced the elevation of Shillong plateau. The spatial variability of $b$-value over this region during 1975 to 2015 is shown in Fig. 3b. We report that low $b$-value is observed in east of Kopli lineament to Bomdila lineament in 


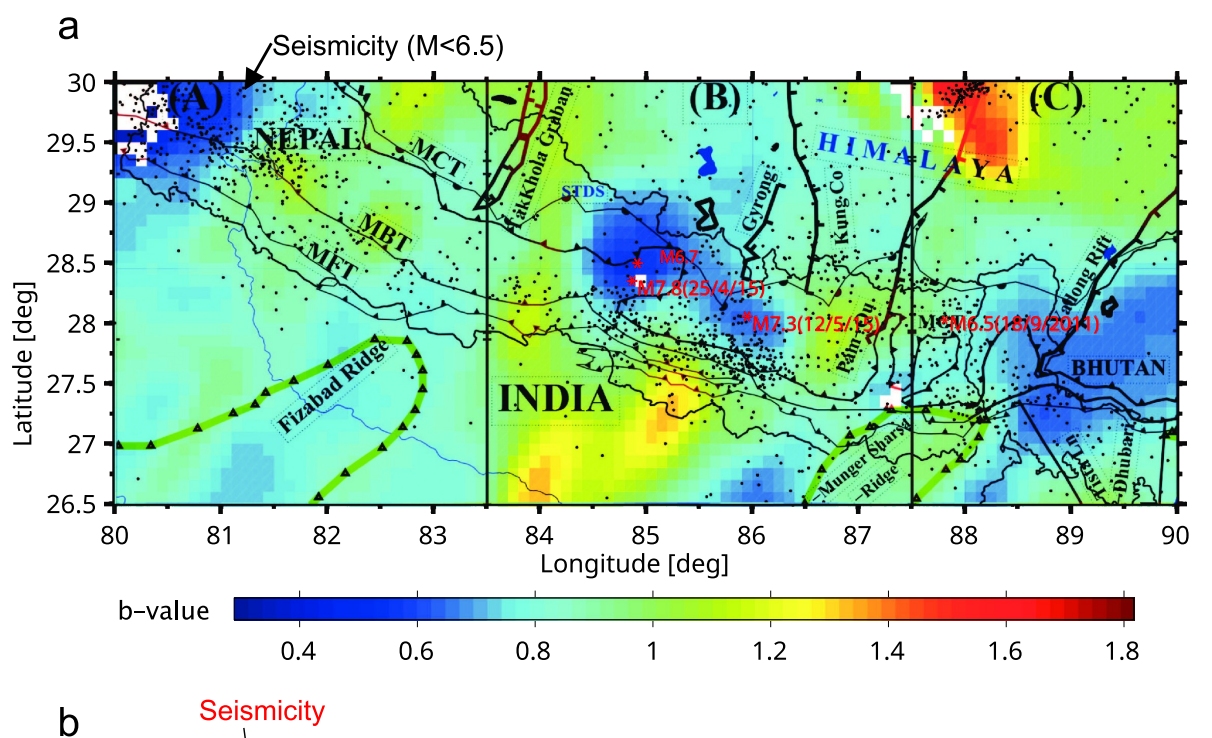

b

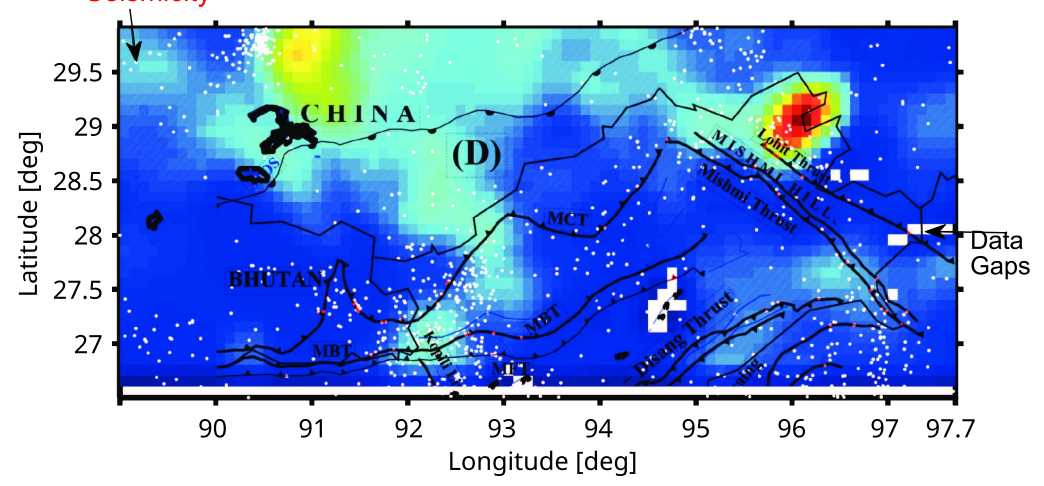

b-value

0.5

1.5

2

2.5

Fig. 3. Spatial variation of the $b$-value for 2 regions: (a) in Nepal, Sikkim and Bhutan region (A, B and $\mathrm{C}$ ) shown with tectonic features - low $b$-value (in light blue colour) coincides with the source region of 25 April and 12 May, 2015 Nepal earthquakes marked as asterisks in red colour; (b) in Bhutan, Assam and Arunachal Pradesh (D region). Black (a) and white (b) dots denote seismicity $\left(3<M_{b}>6.5\right)$ in the regions, white patches indicates loss of information.

southern part of Assam, Tista and Gangtok lineaments and Dhubari fault in western part of Assam and Sikkim-Bhutan. The low $b$-values are along 
Kumar S., Sharma N.: The seismicity of central and north-east Himalayan ... (265-281)

the oblique side of MCT and a region of Mishmi and Lohit thrust in eastern syntaxes zone. The higher $b$-values in central Bhutan indicates large occurrence of small magnitude earthquakes. Eastern Assam and Arunachal Pradesh hosted the great Assam earthquake $\left(28.5^{\circ} \mathrm{N}, 96.7^{\circ} \mathrm{E}\right)$ of August 1950 with $\sim M_{w}$ 8.7. The northern regime of this event shows large $b$-values indicating the high heterogeneity due to the complex geological nature of this regime and could also relate to high pore pressure fluid flow with swarms (Mukhopadhaya, 2015).

In order to study the temporal variation of seismicity over the projected regions $\mathrm{A}, \mathrm{B}, \mathrm{C}$ and $\mathrm{D}$, the $b$-values are derived in bins of 5 years. We interpret the temporal variations of $b$-value and the linear trend to understand the seismicity derived by plate movements in specific sub-divisions. As mentioned earlier, the regions $\mathrm{A}, \mathrm{B}, \mathrm{C}$ and $\mathrm{D}$ are segregated on the basis of geological features like faults, ridge, graben and rift structures (Upreti and LeFort, 1999) which are known to influence the local as well as regional seismicity with time (e.g. Arora et al., 2012; Arora et al., 2014). Regions $\mathrm{A}$ and $\mathrm{B}$ are separated by the Faizabad ridge in the southern portion of MFT and by Takkhola half graben in the north above MCT. Similarly B and $\mathrm{C}$ are separated by the Munger-Sersah ridge towards south of MFT and Pum Qu-Dinggya, Gyrong, Kung Co-Tingri and Xuru Co are graban /normal faults are extended from north of MBT to MCT. Various tectonic forces have further deformed arc shape of MCT into convex shape in this region. The region $\mathrm{C}$ and $\mathrm{D}$ is segmented on basis of seismically active Yadong-Gulu rift, extending from north to south in Sikkim region. While in Southern side, the Tista lineaments, Dhubari faults and Goalpara ridge are influencing seismicity of Himalayan and Shillong plateau (Fig. 1).

Region A, as shown in Fig. 4a, represents the temporal variation of seismic rate over the western Nepal region since 1975. It could be seen that $b$-value does not follow any specific cycle during the early years of the catalogue period (1975-2000). The later stage (2000-2010) shows a strong variability in seismicity over a temporal scale of $\sim 10$ years. Earthquakes of $M \geq 5$ occurred mostly with the decreasing trend of $b$-values variation 1.6 to 0.74 i.e $b$-values $<1$. The moderate to large earthquakes that occurred in the region are also depicted in this Fig. 3a and Fig. 4a-d. One could notice that occurrence of all moderate earthquakes is associated with $b$-values $<1$. As the nature of the $b$-value variability shows an upward trend (1.02), 

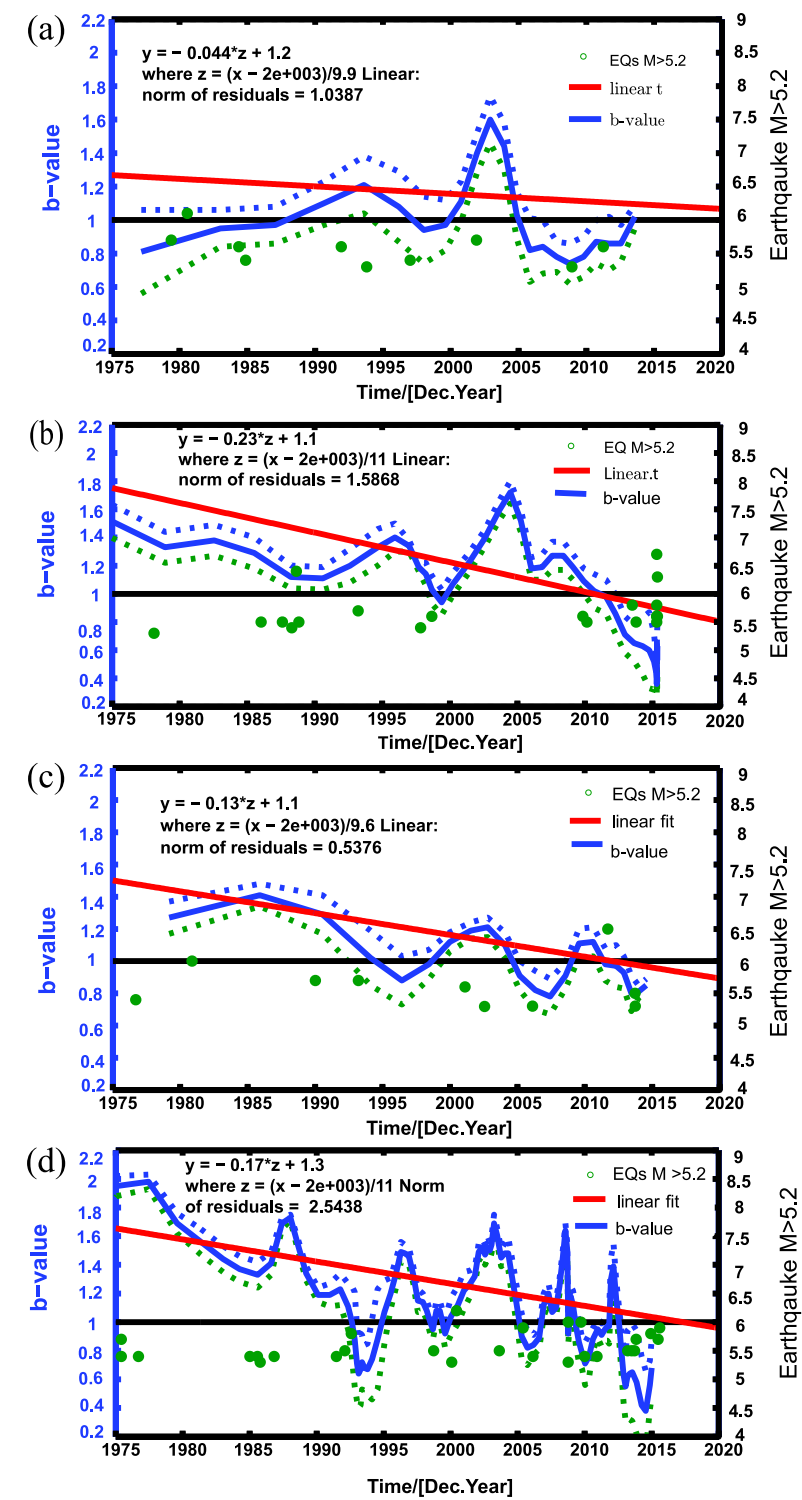

Fig. 4. Temporal variations of $b$-value (a) in A region i.e. western Nepal, (b) in B region i.e. central Nepal, (c) in C region i.e. eastern Nepal and (d) in D region i.e. northeast India during 1975 to 2015 , the earthquakes with $M \geq 5$ are represented by green dots. Solid line indicates the average $b$-value and dashed line indicates \pm 1 sigma. Redline is linear fit of $b$-value variations and black line is for $b$-value $=1.0$. 
Kumar S., Sharma N.: The seismicity of central and north-east Himalayan ... (265-281)

poised to cross the value of 1 ("inflexion point"), we infer that the region is more prone to smaller magnitude earthquakes with magnitude $\leq 5$ in the upcoming periods.

Fig. $4 \mathrm{~b}$ represents the $b$-value variations with time over the central region of Nepal, B region. During the observation span the temporal variability of $b$-value is devoid of any systematic cyclic variations over this region. The positive residuals of $b$-value between 2003 and 2012 depict that the stress accumulation started in 2003 and continued until $\sim 2012$. A couple of earthquakes $M \geq 5.0$ appeared after 2012. The lower trend in $b$-value (1.44 to 0.37) variability between 2012 and 2015 hosted the recent large Nepal earthquake or large volume of moderate earthquakes.

Fig. $4 c$ shows the temporal variations of $b$-value (1.06 to 0.8 ) over eastern Nepal region including Sikkim. It could be observed that $b$-values follow cyclic variability over C-region. The cycle period falls $\sim 10$ years e.g. 1980 with $M \sim 6,1990$ with $M \sim 5.7$ and 2002 with $M \sim 6.0$. The recent major event of Sikkim occurred on 18 September 2011 with $M \sim 6.5$. The further down trend of $b$-value might indicate the occurrence of higher magnitude earthquake $(M>5)$.

The temporal variability of $b$-values over D-region is shown in Fig. $4 \mathrm{~d}$. It could be noticed that the variability is again cyclic with period $\sim 10$ years. The region before 1990 cannot be characterised using $b$-value, as the recorded events were too few. A period of $\sim 10$ years can be clearly emphasised after 1993. The frequent seismic activity after $\sim 2007$ ( $b$-value 1.07) produced more number of earthquakes $(M>5)$. The further lowering trend in $b$-value (0.72 to 0.56$)$ may trigger more earthquakes of similar magnitude range in future.

\section{Conclusions}

The spatial and temporal variations in $b$-values during 1975 to 2015 is analysed over a broad region consisting the central and north-east Himalayan thrust regions. This study reveals the presence of several high and low stressed sub-regions in terms of low and high $b$-value respectively on dipping Indian plate. It is also shown that the locales of high $b$-value indicates the low stressed region and play host to small to moderate earthquakes. While, the regions with low $b$-value indicates the high stressed accumula- 
tion over a period and are likely to spawn moderate to large earthquakes in the following years. The continuous fall of $b$-value for over a decade just before the Nepal earthquake sets a good example to support our argument.

The temporal variations of $b$-value provide fresh insight to the occurrence of impending earthquakes $(M>5$ in the present case) in the demarcated sub-regions. Specifically, in the B region, based on temporal variations of $b$-value, it is found reasonable to state that decrease in $b$-value indicates stress build up and culminated with its release in April, 2015 in the form of the recent Nepal earthquake. In C-region, the cyclic nature of $b$-value variation suggests that moderate to large earthquake occurrence $\left(\sim M_{w} \geq 5\right)$ in this region are periodic with an interval of 10 years. The last occurrence of such an event is the Sikkim earthquake 2011 (shown in Fig. 3a). Finally, in D-region, low $b$-value over Kopli Lineaments and eastern syntax region suggests that the effective stress is accumulating for e.g. in western Bhutan, upper part of Assam \& eastern parts of Arunachal Pradesh near Mishmi hills and the region may experience moderate to large magnitude earthquake in future.

The present study can be appreciated in terms of interpreting the temporal and spatial variations in $b$-value as a tool to depict accumulation of stress in the region (Scholz, 1968; Scholz, 2015; Sreejith et al., 2016; Sreejithy et al., 2018). The cyclic behaviour of temporal variation of $b$-value is representing situation where the subducting Indian plate is locked during inter seismic period and it slips/releases/creeps during co-seismic and post seismic under specific tectonic circumstances. We believe that our study combined with detailed study of the critical geological features and tectonics of strain rate accumulation in the region by combine study of velocity vectors of GPS (Global Position System) and InSAR (Interferometry Synthetic Radar) impending to occurrence of large earthquakes in the the study region.

Acknowledgements. We would like to thank Dr. Stefan Wiemer, of the Swiss Seismological Service, Institute of Geophysics, Swiss Federal Institute of Technology Zurich for ZMAP software (Wiemer, 2001). We also thank P. Wessel and W. H. F. Smith for the GMT software. Susheel Kumar would like to acknowledge the support received from project CLAIMS of Indian Institute of Geomagnetism, Navi Mumbai. Nitin Sharma is thankful to receive the support from Earthquake Hazard Studies of CSIR - National Geophysical Research Institute, Hyderabad 500007, India. 
Kumar S., Sharma N.: The seismicity of central and north-east Himalayan ... (265-281)

\section{References}

Ader T., Avouac J.-P., Liu-Zeng J., Lyon-Caen H., Bollinger L., Galetzka J., Genrich J., Thomas M., Chanard K., Sapkota S. N., Rajaure S., Shrestha P., Ding L., Flouzat M., 2012: Convergence rate across the Nepal Himalaya and interseismic coupling on the Main Himalayan Thrust: Implications for seismic hazard. J. Geophys. Res., 117, B4, B04403, doi: 10.1029/2011JB009071.

Adhikari B. R., Paudyal H., 2015: Spatial Variation of Seismicity in Central Himalayan Region. Himalayan Phys., 5, 47-50, doi: 10.3126/hj .v5i0.12840.

Aki K., 1965: Maximum likelihood estimate of $b$ in the formula $\log _{N}=a-b M$ and its confidence limits. Bull. Earthq. Res. Inst. Univ. Tokyo, 43, 237-239.

Arora B. R., Gahalaut V. K., Kumar N., 2012: Structural control on along-strike variation in the seismicity of the northwest Himalaya. J. Asian Earth Sci., 57, 15-24, doi: 10.1016/j.jseaes . 2012.06.001.

Arora B. R., Prajapati S. K., Reddy C. D., 2014: Geophysical Constraints on the Seismotectonics of the Sikkim Himalaya. Bull. Seismol. Soc. Am., 104, 5, 2278-2287, doi : $10.1785 / 0120130254$.

Avouac J. P., 2003: Mountain building, erosion and the seismic cycle in the Nepal Himalaya. Adv. Geophys., 46, 1-80, doi: 10.1016/S0065-2687(03)46001-9.

Bender B., 1983: Maximum likelihood estimation of $b$-values for magnitude grouped data. Bull. Seismol. Soc. Am., 73, 3, 831-851.

Bhattacharya S. N., Dattatrayam R. S., 2000: Recent advances in seismic instrumentation and data interpretation in India. Curr. Sci., bf 79, 9, 1347-1358.

Bilham R., Gaur V. K., Molnar P., 2001: Himalayan seismic hazard. Science, 293, 5534, 1442-1444, doi: 10.1126/science.1062584.

Bilham R., Larson K., Freymueller J., the Project IDYLHIM Members, 1997: GPS measurements of present-day convergence across the Nepal Himalaya. Nature, 386, 61-64, doi: 10.1038/386061a0.

Caldwell W. B., Klemperer S. L., Lawrence J. F., Rai S. S., Ashish, 2013: Characterizing the Main Himalayan Thrust in the Garhwal Himalaya, India with receiver function CCP stacking. Earth Planet. Sci. Lett., 367, 15-27, doi: 10.1016/j.epsl.2013. 02.009 .

Cattin R., Avouac J.-P., 2000: Modeling mountain building and the seismic cycle in the Himalaya of Nepal. J. Geophys. Res., 105, B6, 13389-13407, doi: 10.1029/2000JB 900032.

Chan C. H., Wu Y. M., Tseng T. L., Lin T. L., Chen C. C., 2012: Spatial and temporal evolution of $b$-values before large earthquakes in Taiwan. Tectonophysics, 532-535, 215-222, doi: 10.1016/j.tecto.2012.02.004.

Dal Zilio L., Dinther Y., Gerya T., Avouac J.-P., 2019: Bimodal seismicity in the Himalaya controlled by fault friction and geometry. Nat. Commun., 10, 48, doi: 10.1038/s414 67-018-07874-8.

Fitch T. J., 1970: Earthquake mechanisms in the Himalayan, Burmese, and Andaman Regions and continental tectonics in central Asia. J. Geophys. Res., 75, 4, 26992709, doi : 10.1029/JB075i014p02699. 
Gansser A., 1964: The Geology of the Himalayas. Wiley Interscience, New York, 289 p.

Gutenberg B., Richter C. F., 1954: Seismicity of the Earth and Associated Phenomena. Princeton University Press, Princeton, N.J., USA, 2nd edn., 310 p.

Gutenberg B., Richter C. F., 1944: Frequency of earthquakes in California. Bull. Seismol. Soc. Am., 34, 185-188.

Ishimoto M., Iida K., 1939: Observations of earthquakes registered with the recently constructed microseismograph (Observations sur les séismes enregistrés par le microsismographe construit dernièrement). Bull. Earthq. Res. Inst. Univ. Tokyo, 17, 443-478 (in Japanese with French abstract).

Jade S., Mukul M., Bhattacharyya A. K., Vijayan M. S. M., 2007: Estimates of interseismic deformation in Northeast India from GPS measurements. Earth Planet. Sci. Lett., 263, 3-4, 221-234, doi: 10.1016/j.eps1.2007.08.031.

Jade S., Mukul M., Gaur V. K., Kumar K., Shrungeshwar T. S., Satyal G. S., Dumka R. K., Jagannathan S., Ananda M. B., Kumar P. D., Banerjee S,, 2014: Contemporary deformation in the Kashmir-Himachal, Garhwal and Kumaon Himalaya: Significant insights from 1995-2008 GPS time series. J. Geodesy., 88, 6, 539-557, doi : $10.1007 / \mathrm{s} 00190-014-0702-3$.

Kayal J. R., 2001: Microearthquake activity in some parts of the Himalaya and tectonic model. Tectonophysics, 339, 3-4, 331-351, doi : 10.1016/S0040-1951(01)00129-9.

Kayal J. R., 2010: Himalayan tectonic model and the great earthquakes: an appraisal. Geomat. Nat. Haz. Risk, 1, 1, 51-67, doi : 10.1080/19475701003625752.

Molnar P., Lyon-Caent H., 1989: Fault plane solutions of earthquakes and active tectonics of Tibetan Plateau and its margins. Geophys. J. Int., 99, 1, 123-153, doi: 10.1111/j.1365-246X.1989.tb02020.x.

Mukhopadhyay B., 2011: Clusters of Moderate Size Earthquakes along Main Central Thrust (MCT) in Himalaya, Int. J. Geosci., 2, 3, 318-325, doi: 10.4236/ijg. 2011 .23034 .

Mukhopadhyay B., Dasgupta S., 2015: Earthquake swarms near eastern Himalayan Syntaxis along Jiali Fault in Tibet: A seismotectonic appraisal. Geosci. Front., 6, 5, 715-722, doi: 10.1016/j.gsf.2014.12.009.

Mukul M., Jade S., Bhattacharyya A. K., Bhusan K., 2010: Crustal shortening in convergent orogens: Insights from Global Positioning System (GPS) measurements in India. J. Geol. Soc. India, 75, 1, 302-312, doi: 10.1007/s12594-010-0017-9.

Ni J., Barazangi M., 1984: Seismotectonics of the Himalayan collision zone: Geometry of the under thrusting Indian Plate beneath the Himalaya. J. Geophys. Res., 89, B2, 1147-1163, doi: 10.1029/JB089iB02p01147.

Nuannin P., Kulhanek O., Persson L., 2005: Spatial and temporal b-value anomalies preceding the devastating off coast of NW Sumatra earthquake of December 26, 2004. Geophys. Res. Lett., 32, 11, L11307, doi: 10.1029/2005GL022679.

Ogata Y., Katsura K., 1993: Analysis of temporal and spatial heterogeneity of magnitude frequency distribution inferred from earthquake catalogues. Geophys. J. Int., 113, 3, 727-738, doi: 10.1111/j.1365-246X.1993.tb04663.x. 
Kumar S., Sharma N.: The seismicity of central and north-east Himalayan ... (265-281)

Pandey M. R., Tandukar R. P., Avouac J. P., Lavé J., Massot J. P., 1995: Interseismic strain accumulation on the Himalaya crustal ramp (Nepal). Geophys. Res. Lett., 22, 7, 751-754, doi : 10.1029/94GL02971.

Pandey M. R., Tandukar R. P., Avouac J. P., Vergne J., Héritier Th., 1999: Seismotectonics of the Nepal Himalaya from a local seismic network. J. Asian Earth Sci., 17, 5-6, 703-712, doi : 10.1016/S1367-9120(99)00034-6.

Parsons T., 2007: Forecast experiment: Do temporal and spatial $b$-value variations along the Calaveras fault portend $M \geq 4.0$ earthquakes? J. Geophys. Res., 112, B3, B03308, doi : 10.1029/2006JB004632.

Prasad S., Singh C., 2015: Evolution of b-values before large earthquakes of $\mathrm{mb} \geq 6.0$ in the Andaman region. Geol. Acta, 13, 3, 205-210, doi : 10.1344/GeologicaActa2015.13 .3.3.

Pudi R., Roy P., Martha T. R., Kumar K. V., Rao P. R., 2018: Spatial Potential Analysis of Earthquakes in the Western Himalayas Using $b$-value and Thrust Association. J. Geol. Soc. India, 91, 6, 664-670, doi : 10.1007/s12594-018-0921-y.

Rydelek P. A., Sacks I. S., 1989: Testing the completeness of earthquake catalogues and the hypothesis of self-similarity. Nature, 337, 251-253, doi: 10.1038/337251a0.

Sapkota S. N., Bollinger L., Klinger Y., Tapponnier P., Gaudemer Y., Tiwari D., 2013: Primary surface rupture of the great Himalayan earthquakes of 1934 and 1255 . Nat. Geosci., 6, 71-76, doi : 10.1038/ngeo1669.

Schelling D., Arita K., 1991: Thrust tectonics, crustal shortening and the structure of the far-eastern Nepal Himalaya. Tectonics, 10, 5, 851-862, doi: 10.1029/91TC01011.

Scholz C. H., 1968: The frequency-magnitude relation of microfracturing in rock and its relation to earthquakes. Bull. Seism. Soc. Am., 58, 1, 399-415.

Scholz C. H., 2015: On the stress dependence of the earthquake $b$ value. Geophysics Res. Lett., 42, 5, 1399-1402, doi: 10.1002/2014GL062863.

Sreejith K. M., Sunil P. S., Agrawal R., Saji A. P., Ramesh D. S., Rajawat A. S., 2016: Coseismic and early post seismic deformation due to the 25 April 2015, $M_{w} 7.8$ Gorkha, Nepal, earthquake from InSAR and GPS measurements. Geophysical Research Letters, 43, 7, 3160-3168, doi: 10.1002/2016GL067907.

Sreejith K. M., Sunil P. S., Agrawal R., Saji A. P., Rajawat A. S., Ramesh D. S., 2018: Audit of stored strain energy and extent of future earthquake rupture in central Himalaya. Scientific Reports volume 8, Article number: 16697.

Thakur V. C., 2004: Active tectonics of Himalayan Frontal Thrust and Seismic Hazard to Ganga Plain. Curr. Sci., 86, 11.

Tsapanos T. M., 1990: b-values of two tectonic parts in the Circum Pacific belt. Pure Appl. Geophys., 134, 2, 229-242, doi: 10.1007/BF00876999.

Uhrhammer R., 1986: Characteristics of northern and southern California seismicity. Earthquake Notes, 57, 1, 21.

Upreti B. N., LeFort P., 1999: Lesser Himalayan crystalline nappes of Nepal: Problems their origin. In: Macfarlane A., Sorkhabi R. B., Quade J.: Himalaya and Tibet: Mountain Roots to Mountain Tops, Geol. Soc. Am. Spec. Pap., 328, 225-238, doi : $10.1130 / 0-8137-2328-0.225$. 
Utsu T., 1999: Representation and analysis of the earthquake size distribution: a historical review and some new approaches. Pure Appl. Geophys., 155, 2-4, 509-535, doi : $10.1007 / \mathrm{s} 000240050276$.

Valdia K. S, 1976: Himalayan transverse fault and their parallelism with subsurface structures of north its aftershocks Indian plane. Tectonophysics, 32, 3-4, 353-386, doi : 10.1016/0040-1951(76)90069-X.

Wyss M., 1973: Towards a physical understanding of the earthquake frequency distribution. Geophys. J. R. Astro. Soc., 31, 4, 341-359, doi: 10.1111/j.1365-246X.1973 .tb06506.x.

Wiemer S., 2001: A software package to analyze seismicity: ZMAP. Seismol. Res. Lett., $\mathbf{7 2}, 374-383$.

Woessner J., Wiemer S., 2005: Assessing the quality of earthquake catalogues: Estimating the magnitude of completeness and its uncertainty. Bull. Seismol. Soc. Am., 95, doi: $10.1785 / 012040007$.

Yeats R. S., Thakur V. C., 1998: Reassessment of earthquake hazard based on a faultbend fold model of the Himalayan plate-boundary fault. Curr. Sci., 74, 3, 230-233.

Zhao L.-S., Helmberger D. V., 1991: Geophysical implications from relocations of Tibetan earthquakes; Hot lithosphere. Geophys. Res. Lett., 18, 12, 2205-2208, doi : 10.1029 /91g102865.

Zhao W., Nelson K. D., Che J., Quo J., Lu D., Wu C., Liu X., 1993: Deep seismic reflection evidence continental under thrusting beneath southern Tibet. Nature, 366, $6455,577-559$, doi: $10.1038 / 366557 \mathrm{a} 0$. 